\title{
ENTERIC ROTA AND CORONA VIRUSES INFECTION IN NEONATAL CALVES
}

\author{
AHMED M.A. ZAITOUN; OSAMA ABDEL-HAKIM and ZAINAB M.A. YOUSSEF \\ Infectious Diseases, Department of Animal Medicine, Faculty of Veterinary \\ Medicine, Assiut University, Egypt
}

Received: 5 November 2017;

Accepted: 3 December 2017

\begin{abstract}
Calf diarrhea is a common syndrome causing colossal economic losses. Rotavirus and Coronavirus are major pathogens of calf diarrhea. During the period of investigation (13 consecutive months), a total number of 140 neonatal calves were carefully examined and thereafter subjected to serological and molecular diagnosis for the diagnosis of Rota and Corona viruses' infection. The serological and molecular diagnosis by using LAT and RTPCR indicated that positive samples of Rotavirus infection were $21.43 \%$ (30/140) and 8\% (4/50), respectively. ELISA and RT-PCR were used in diagnosing of BCoV infection and found that positive samples were $2.13 \%$ (2/94) and 4\% (2/50), respectively. The Prevalence of Rotavirus and Coronavirus infection was $21.43 \%$ (30/140) and $2.13 \%(2 / 94)$ of the examined calves, respectively. It was found that there was a strong negative correlation between age of examined calves and Rotavirus infection. Coronavirus infection was found in calves at >4-7 weeks. There were no significance difference in Rota and Corona viruses' infection and sex, breed and species of examined calves. The most positive cases of Rotavirus and Coronavirus infection were reported in cold months. The lower infection rate of Rotavirus was recorded in hot months. It is concluded that Rota and Corona viruses play an outstanding role in causing enteritis in neonatal calves in different localities of Assiut governorate.
\end{abstract}

Key words: Rotavirus, Coronavirus, LAT, ELISA, RT-PCR, Epidemiology.

\section{INTRODUCTION}

Neonatal calves are the backbone of animal resources for dairy or beef industries (Andrews et al., 2004). Pneumonia and enteritis appear to be the prominent problems deter the healthy condition of calves during the early days of their life. Enteritis appears to be more problematic and cause a considerable level of economic losses (Mushtaq et al., 2013). Enteritis is a complex multi-factorial etiology, usually influenced by nutritional and environmental factors as well as management practices in association with infectious agents (Mohammed et al., 2017). There are enormous pathogens encountered as enteropathogens. However, Enterotoxigenic K99+ Escherichia coli, followed by Rotavirus, Coronavirus and the protozoan Cryptosporidium parvum are commonly reported endemic micro-organisms associated with neonatal calf diarrhea (Rocha et al., 2017). The infectious agents such as Rota and Corona viruses' appear to be more serious enteropathogens in neonatal calves (Cockcroft, 2015). Both Rotavirus and Coronavirus can induce intestinal villous atrophy

Corresponding author: Dr. ZAINAB M.A. YOUSSEF

E-mail address: zeinabmohammed613@yahoo.com

Present address: Infectious Diseases, Department of Animal Medicine, Faculty of Veterinary Medicine, Assiut University, Egypt which leads to malabsorption and maldigestion (Zachary and McGavin, 2013 and Ammar et al., 2014). Bovine Coronavirus enteritis is more severe than bovine Rotavirus because it affects small and large intestine as well as it causes respiratory tract infection (Dash et al., 2012 and Hansa et al., 2012). Diagnosis of Rota and Corona viruses' enteritis depending on clinical signs is unfeasible. Consequently, the clinically suspected cases must be confirmed by laboratory tests (Mayameei et al., 2010). Laboratory diagnosis of both viruses in calves' enteritis depends on identification of viral antigens then nucleic acids in fecal samples. Latex agglutination test (LAT) and Enzyme linked immunosorbent assay (ELISA) are rapid, sensitive, specific tests and need shorter time than viral isolation for Rota and Corona viral antigen detection. Virus confirmation can be done at genomic level by molecular method of reverse transcriptase polymerase chain reaction (RT-PCR) (Singh and Jhala, 2011; Dash et al., 2012 and Sravani et al., 2014). Detection of clinical findings, laboratory diagnosis and epidemiological studies of both BRV and $\mathrm{BCoV}$ in calves in Assiut appear to be scanty. Therefore the current work aimed to investigate the clinical findings of enteric calves with serological, molecular and epidemiological investigation of bovine Rota and Corona viruses in neonatal calves. 


\section{MATERIALS AND METHODS}

\begin{abstract}
Animals
During the period of investigation, from December 2015 to December 2016, a total of 140 examined neonatal calves of different ages, sex, breed and species were belonged to different farms. Besides, individual cases were from different localities in Assiut Governorate that admitted to Veterinary Teaching Hospital, Faculty of Veterinary Medicine, Assiut University.
\end{abstract}

\section{Clinical examination}

Clinical examination of investigated calves was carried out according to (Jackson and Cockcroft, 2002).

\section{Sampling}

All fecal samples were collected from enteric and clinically healthy neonatal calves in sterile plastic cups for serological and molecular diagnosis.

\section{Serological diagnosis}

\section{a- Serological detection of Rotavirus antigen by LAT}

All 140 fecal samples were subjected to LAT for detection of Rotavirus antigen by a commercial kit (REF-M80 Rotascreen ${ }^{\circledR}$ kit Microgen Bioproducts limited, United Kingdom).

\section{b- Serological detection of Coronavirus antigen by ELISA}

The 94 fecal samples were subjected to ELISA for detection of Coronavirus antigen by a commercial kit (Antigenic ELISA kit for detection of Coronavirus, Bio-x Diagnostics S.P.R.L., Belgium, BIO K 344/2) and following the protocol as per the manufacture's instruction. The results were interpreted by using OD value obtained at $450 \mathrm{~nm}$ using ELISA reader (Sunrise absorbance reader, Tecan, Austria).

\section{Molecular diagnosis \\ Molecular detection of Rota and Corona viral nucleic acid by RT-PCR}

a- RNA extraction

50 fecal samples were used for extraction of viral RNA by using a QIAamp Viral RNA Mini Kit (Qiagen, Hilden, Germany) according to the manufacturer's instructions.

\section{b- RT-PCR}

In case of Rotavirus, all extracted RNAs were denatured at $97^{\circ} \mathrm{C}$ for $3 \mathrm{~min}$ and immediately placed on ice (Fukuda et al., 2013).Then, OneStep RT-PCR was performed by using Qiagen OneStep RT-PCR Kit (Qiagen, Hilden, Germany) according the manufacture's instruction in both Rota and Corona viruses. The primers pair used for amplification of VP7 gene of bovine Rotavirus. The sequences of these primers were as follows: upstream primer: 5'GGC TTT AAA AGA GAG AAT TTC CGT CTG G3', downstream primers: 5'- GGT CAC ATC ATA CAA TTC TAA TCT AAG -3' (Gouvea et al., 1990 and Sravani et al., 2014). But the primers pair used for amplification of $\mathrm{N}$ gene of bovine Coronavirus. The sequences of these primers were as follows: upstream primer: 5'-GCA ATC CAG TAG TAG AGC GT-3', downstream primers: 5'-CTT AGT GGC ATC CTT GCC AA-3' (Cho et al., 2001). The amplified products were visualized on agarose gel stained with Ethidium bromide and photographed by a gel documentation system (BDA digital Biometra, Germany). The RT-PCR products of Rotavirus of 1062 bp were visualized on $1 \%$ agarose gel but the RT-PCR products of Coronavirus of $730 \mathrm{bp}$ visualized on $1.5 \%$ agarose gel.

\section{Statistical analysis}

The data were analyzed by Chi-square of independence and correlation according to Statistical package for the social sciences (SPSS) version 16 software program (2007).

\section{RESULTS}

\section{Clinical findings}

Clinical findings revealed that the investigated enteric calves were showed classic signs of enteritis which suffering from variable degree of diarrhea, dehydration, weakness, reluctance to move, recumbence with signs of comatose. Some of examined calves were suffering from emaciation and straining with or without arched back (Fig. 1). In addition to enteritis, signs of respiratory embarrassment in form of nasal discharge, cough and signs of dyspnea were observed in some cases of enteric calves. Regarding to fecal characters of enteric calves, the fecal consistency differ from normal to profuse watery. The color of fecal discharge varied from pale yellowish, yellowish to greenish and some of fecal samples contained mucus with or without undigested food and clotted blood (Fig. 2).

\section{Serological diagnosis}

\section{a- Serological diagnosis of Rotavirus antigen by} using LAT

Of a total 140 examined fecal samples for Rotavirus antigen, $30(21.43 \%)$ were serologically positive by LAT as indicated by clear agglutination of latex particles in tested samples (Fig. 3).

\section{b- Serological diagnosis of Coronavirus antigen by using ELISA}

Our result revealed that $2(2.13 \%)$ of 94 examined fecal samples were serologically positive.

\section{Molecular diagnosis \\ a- Molecular diagnosis of Rotavirus nucleic acid}


Four $(8 \%)$ of 50 fecal samples were molecularly positive. The specific band showed at 1062 bp after PCR amplification of VP7 gene of Rotavirus (Fig. 4).

\section{b- Molecular diagnosis of Coronavirus nucleic acid}

Our result revealed that $2(4 \%)$ out of 50 fecal samples were molecularly positive. The specific band showed at 730 bp after PCR amplification of $\mathrm{N}$ gene of Coronavirus (Fig. 5).

\section{Epidemiological findings}

\section{a- Percent of infection}

The present study indicated that percentage of Rotavirus infection was $21.43 \%$ (30/140) of investigated neonatal calves, while percentage of Coronavirus infection was $2.13 \%$ (2/94) of examined neonatal calves (Table 1). The percentage of Rotavirus infection among the enteric calves was $23.33 \%(28 / 120)$ and $10 \%$ (2/20) among clinically healthy calves, while percentage of Coronavirus infection among enteric calves was $2.20 \%(2 / 91)$ and $0 \%(0 / 3)$ among clinically healthy calves (Table 2$)$. Regarding to locality, the infection of Rotavirus was $23.08 \%$ (15 of 65 ) of fecal samples collected from calves that came to Veterinary Teaching Hospital, while prevalence was $20 \%$ ( 15 of 75 ) of tested fecal samples of calves of different farms in Assiut Governorate. The positive cases of Coronavirus infection was detected only in investigated enteric calves in farms (Table 3 ).

\section{b- Age susceptibility}

The rate of Rotavirus infection was studied in calves at age groups of 3 days-1week, $>1-2,>2-3,>3-4,>4$ -
5, $>5-7$ and $>7-12$ weeks and yielding $57.14 \%$, $45.46 \%, 33.33 \%, 16 \%, 14.29 \%, 19.23 \%$ and $10.26 \%$, respectively of 140 of examined calves. Coronavirus infection was observed among enteric calves of $>4-5$ weeks old by $9.09 \%(1 / 11)$ and $>5-7$ weeks old by $6.25 \%(1 / 16)$ of investigated calves (Table 4 \& Fig. $6)$.

\section{c- Effect of sex}

The analytic results indicated that there was no significant difference in percentage of both Rota and Corona viruses' infection between male and female calves (Table 5).

\section{d- Breed susceptibility}

In the present study, there was no significant difference in percentage of Rota and Corona viruses' infection between Native, Friesian ad Holstein breeds (Table 6).

\section{e- Species susceptibility}

Rotavirus infection was diagnosed in both cattle and buffalo calves' fecal samples. It's found $22.14 \%$ of cattle calves were positive to Rotavirus, where $11.11 \%$ of buffalo calves were positive. Coronavirus infection was diagnosed among cattle calves $(2.25 \%)$ and no infection among buffalo calves was reported (Table 7).

\section{f- Seasonal variation}

Our result indicated that percentage of Rotavirus infection in examined calves was in cold months $(26.97 \%)$ and was $(11.77 \%)$ in hot months. Percentage of Coronavirus infection was detected in cold months only by $3.45 \%$ (Table $8 \&$ Fig. 7).

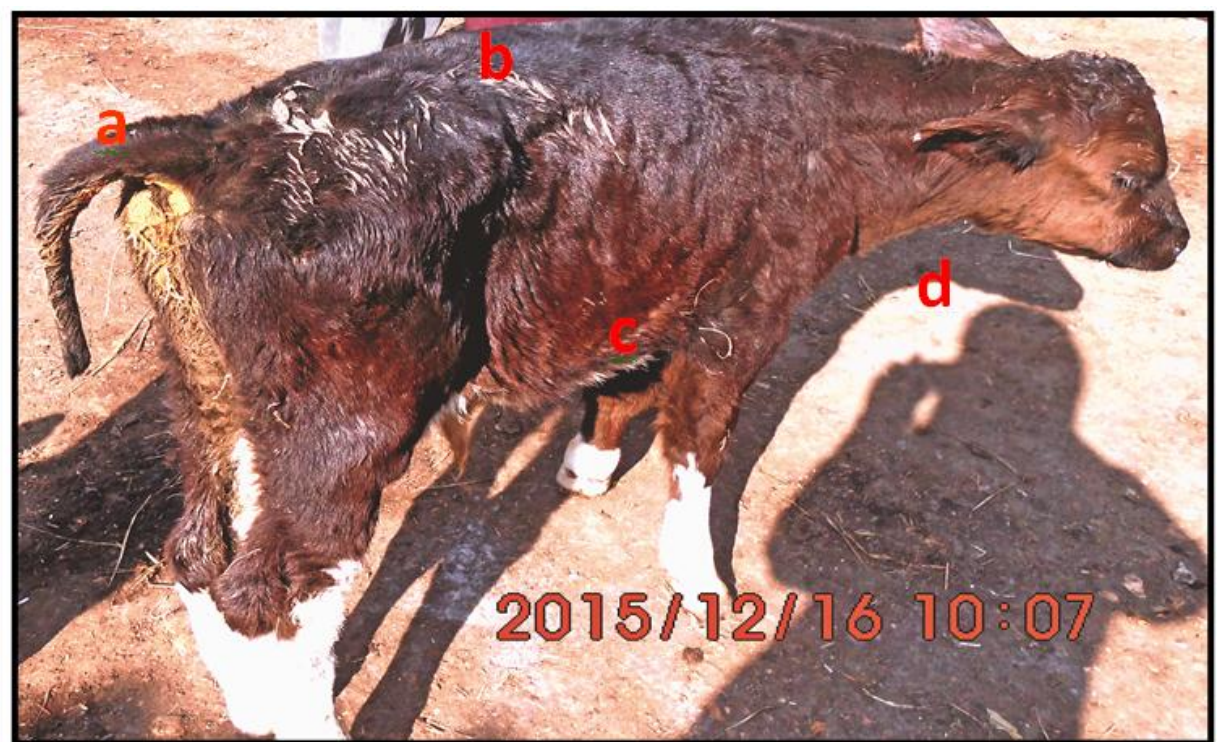

Figure 1: Frequent attempts of an enteric calf to evacuate the intestinal contents. Note: (a) Raising the tail with lateral deviation, (b) Arched back, (c) Abdominal tucked-up (d) Extension of head and neck. 


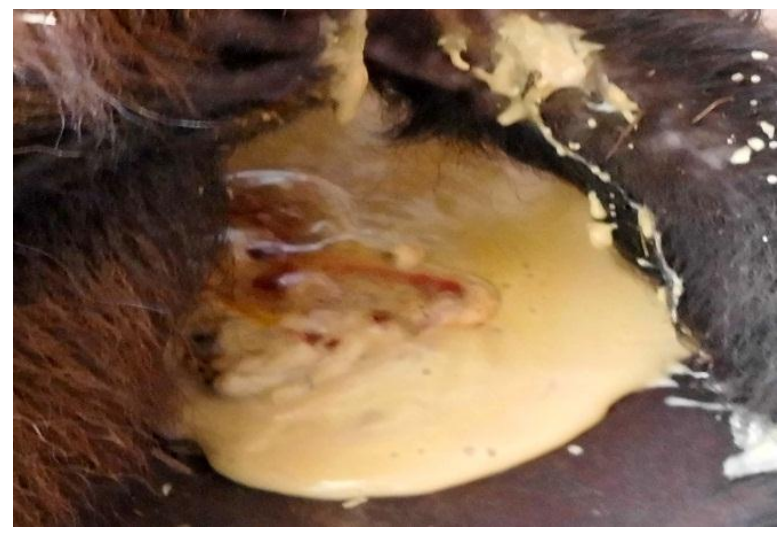

Figure 2: Close-up photograph on an

enteric native breed calf discharging extra-mucoid yellowish fecal discharge similar viscous lentil soup containing various sizes of particles of indigestible food materials and flakes of blood clots.
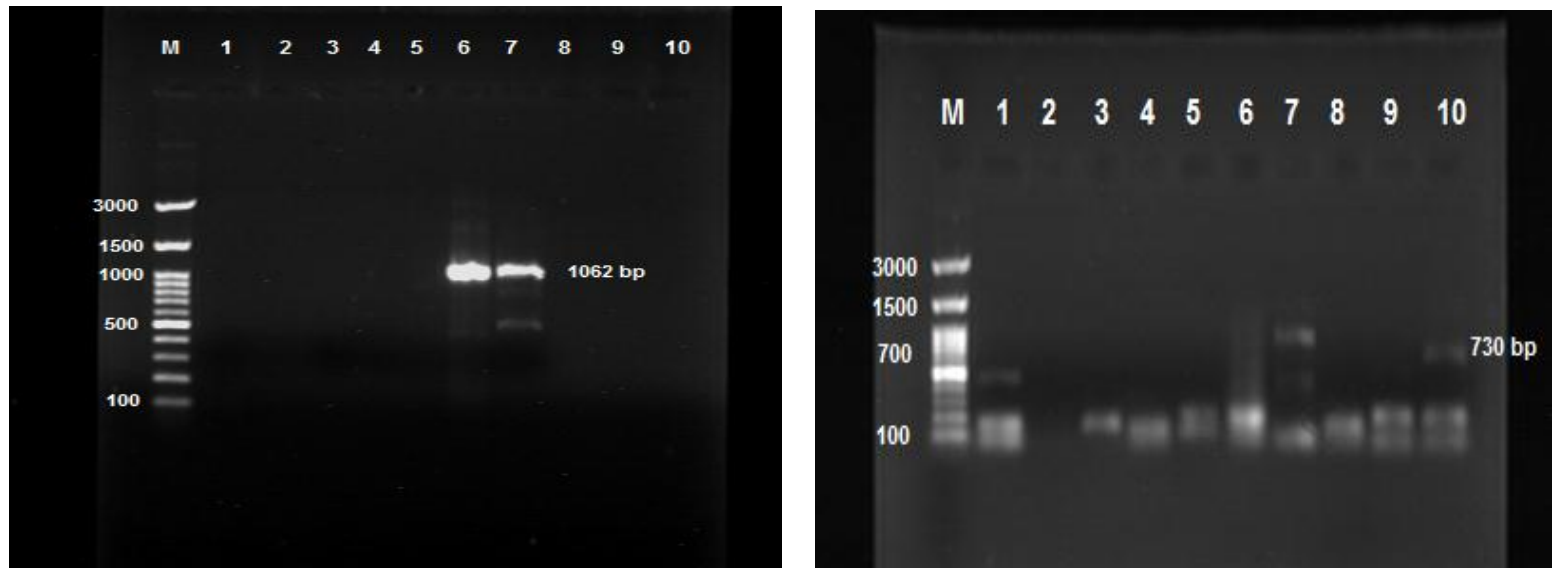

Figure 4: Agarose gel electrophoresis of RT-PCR amplification of VP7 gene of Rotavirus. Lane M: DNA Marker of $100 \mathrm{bp}$, lanes 6, 7: positive samples with amplified product at $1062 \mathrm{bp}$, lanes 1, 2, 3, 4, 5, $8,9 \& 10$ : negative samples.

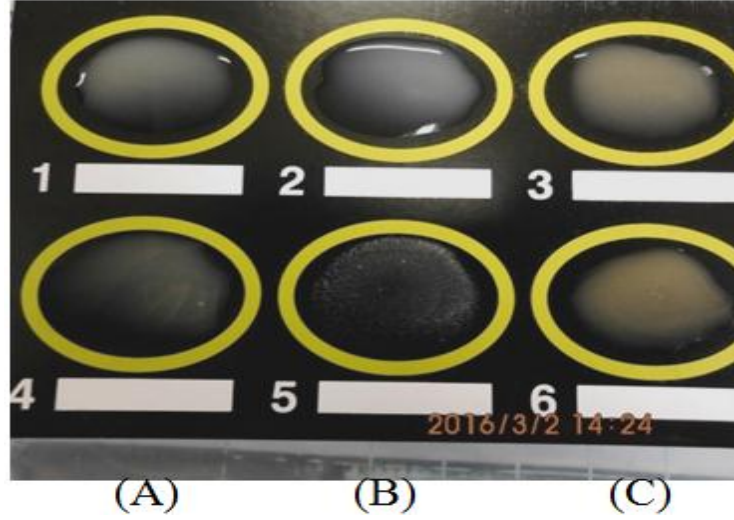

Figure 3: LAT for detection of Rotavirus antigen $\left(\mathrm{A}_{1,4}\right)$ and $\left(\mathrm{C}_{3,6}\right)$ Negative results (milky suspension). ( $\left.\mathrm{B}_{2,5}\right)$ Positive result (agglutination).
Figure 5: Agarose gel electrophoresis of RT-PCR amplification of $\mathrm{N}$ gene of Coronavirus. Lane $\mathrm{M}$ : DNA Marker of $100 \mathrm{bp}$, lanes 10: positive sample with amplified product at $730 \mathrm{bp}$, lane $1,2,3,4,5,6$, 7, 8 \& 9: negative samples.

Table 1: Percentage of Rota and Corona viruses' infection in examined calves.

\begin{tabular}{cccc}
\hline Viral enteropathogens & $\begin{array}{c}\text { Number of examined } \\
\text { calves }\end{array}$ & Positive & Percentage \\
\hline Rotavirus & 140 & 30 & $21.43 \%$ \\
\hline Coronavirus & 94 & 2 & $2.13 \%$ \\
\hline
\end{tabular}

Table 2: Occurrence of Rota and Corona viruses' infection in enteric and the clinically healthy calves.

\begin{tabular}{ccccccc}
\hline & \multicolumn{3}{c}{ Rotavirus infection } & \multicolumn{3}{c}{ Coronavirus infection } \\
\cline { 2 - 7 } & $\mathbf{N}^{\mathbf{*}}$ & Positive & $\boldsymbol{\%}$ & $\mathbf{N}^{\mathbf{0}}$ & Positive & $\%$ \\
\hline Enteric calves & 120 & 28 & 23.33 & 91 & 2 & 2.20 \\
\hline Clinically healthy calves & 20 & 2 & 10 & 3 & 0 & 0 \\
\hline Total & 140 & 30 & 21.43 & 94 & 2 & 2.13 \\
\hline
\end{tabular}

No significant variation at $\mathrm{p}<0.05$ 
Table 3: Distribution of Rota and Corona viruses' infection in examined calves in different localities.

\begin{tabular}{cccccccc}
\hline \multirow{2}{*}{ Origin } & \multicolumn{3}{c}{ Rotavirus infection } & \multicolumn{3}{c}{ Coronavirus infection } \\
\cline { 2 - 8 } & $\mathbf{N}^{\mathbf{*}}$ & Positive & $\%$ & $\mathbf{N}^{\mathbf{0}}$ & Positive & $\%$ \\
\hline Individual cases* & 65 & 15 & 23.08 & 38 & 0 & 0 \\
\hline Farms & 75 & 15 & 20 & 56 & 2 & 3.57 \\
\hline Total & 140 & 30 & 21.43 & 94 & 2 & 2.13 \\
\hline
\end{tabular}

* admitted from various area of Assiut to Veterinary Teaching Hospital No significant variation at $\mathrm{p}<0.05$

Table 4: Age susceptibility to Rota and Corona viruses' infection in investigated calves.

\begin{tabular}{ccccccc}
\hline $\begin{array}{c}\text { Age groups } \\
\text { (weeks) }\end{array}$ & \multicolumn{3}{c}{ Rotavirus infection } & \multicolumn{3}{c}{ Coronavirus infection } \\
\cline { 2 - 7 } & $\mathbf{N}^{\mathbf{*}}$ & Positive & $\boldsymbol{\%}$ & $\mathbf{N}^{\mathbf{0}}$ & Positive & $\%$ \\
\hline 3 days-1week & 7 & 4 & $57.14^{* *}$ & 4 & 0 & 0 \\
\hline$>\mathbf{1 - 2}$ & 11 & 5 & 45.46 & 8 & 0 & 0 \\
\hline$>\mathbf{2 - 3}$ & 18 & 6 & 33.33 & 13 & 0 & 0 \\
\hline$>\mathbf{3 - 4}$ & 25 & 4 & 16 & 15 & 0 & 0 \\
\hline$>\mathbf{4 - 5}$ & 14 & 2 & 14.29 & 11 & 1 & 9.09 \\
\hline$>\mathbf{5 - 7}$ & 26 & 5 & 19.23 & 16 & 1 & 6.25 \\
\hline$>\mathbf{7 - 1 2}$ & 39 & 4 & 10.26 & 27 & 0 & 0 \\
\hline Total & 140 & 30 & 21.43 & 94 & 2 & 2.13 \\
\hline
\end{tabular}

** Highly significant negative correlation at $\mathrm{P}<0.01$

Table 5: Effect of sex on both Rota and Corona viruses' infection in examined calves.

\begin{tabular}{ccccccc}
\hline Sex & \multicolumn{3}{c}{ Rotavirus infection } & \multicolumn{3}{c}{ Coronavirus infection } \\
\cline { 2 - 7 } & $\mathrm{N}^{\mathrm{o}}$. & Positive & $\%$ & $\mathrm{~N}^{\mathrm{o}}$ & Positive & $\%$ \\
\hline Male & 85 & 22 & 25.88 & 58 & 2 & 3.45 \\
\hline Female & 55 & 8 & 14.55 & 36 & 0 & 0 \\
\hline Total & 140 & 30 & 21.43 & 94 & 2 & 2.13 \\
\hline
\end{tabular}

No significant at $\mathrm{p}<0.05$

Table 6: Breed susceptibility to both Rota and Corona viruses' infection in investigated calves.

\begin{tabular}{ccccccc}
\hline Breed & \multicolumn{3}{c}{ Rotavirus infection } & \multicolumn{3}{c}{ Coronavirus infection } \\
\cline { 2 - 7 } & $\mathbf{N}^{\mathbf{0}}$ & Positive & $\%$ & $\mathbf{N}^{\mathbf{0}}$ & Positive & $\%$ \\
\hline Native (balady) & 54 & 10 & 18.52 & 35 & 2 & 5.71 \\
\hline Friesian & 49 & 11 & 22.45 & 36 & 0 & 0 \\
\hline Holstein & 37 & 9 & 24.32 & 23 & 0 & 0 \\
\hline Total & 140 & 30 & 21.43 & 94 & 2 & 2.13 \\
\hline
\end{tabular}

No significant variation at $\mathrm{p}<0.05$ 
Table 7: Detection of Rota and Corona viruses' infection in investigated calves according to species.

\begin{tabular}{ccccccc}
\hline Species & \multicolumn{3}{c}{ Rotavirus infection } & \multicolumn{3}{c}{ Coronavirus infection } \\
\cline { 2 - 7 } & $\mathrm{N}^{\circ}$. & Positive & $\%$ & $\mathrm{~N}^{\circ}$. & Positive & $\%$ \\
\hline Cattle calves & 131 & 29 & 22.14 & 89 & 2 & 2.25 \\
\hline Buffalo calves & 9 & 1 & 11.11 & 5 & 0 & 0 \\
\hline Total & 140 & 30 & 21.43 & 94 & 2 & 2.13 \\
\hline
\end{tabular}

No Significant variation at $\mathrm{p}<0.05$

Table 8: Detection of both Rota and Corona viruses' infection in examined calves according to seasonal variation.

\begin{tabular}{ccccccc}
\hline \multirow{2}{*}{ Seasons } & \multicolumn{3}{c}{ Rotavirus infection } & \multicolumn{2}{c}{ Coronavirus infection } \\
\cline { 2 - 7 } & No. & Positive & $\%$ & No. & Positive & $\%$ \\
\hline Cold months (from October to February) & 89 & 24 & $26.97 *$ & 58 & 2 & 3.45 \\
\hline Hot months (from March to September) & 51 & 6 & 11.77 & 36 & 0 & 0 \\
\hline Total & 140 & 30 & 21.43 & 94 & 2 & 2.13 \\
\hline
\end{tabular}

* Significant increase at $\mathrm{p}<0.05$

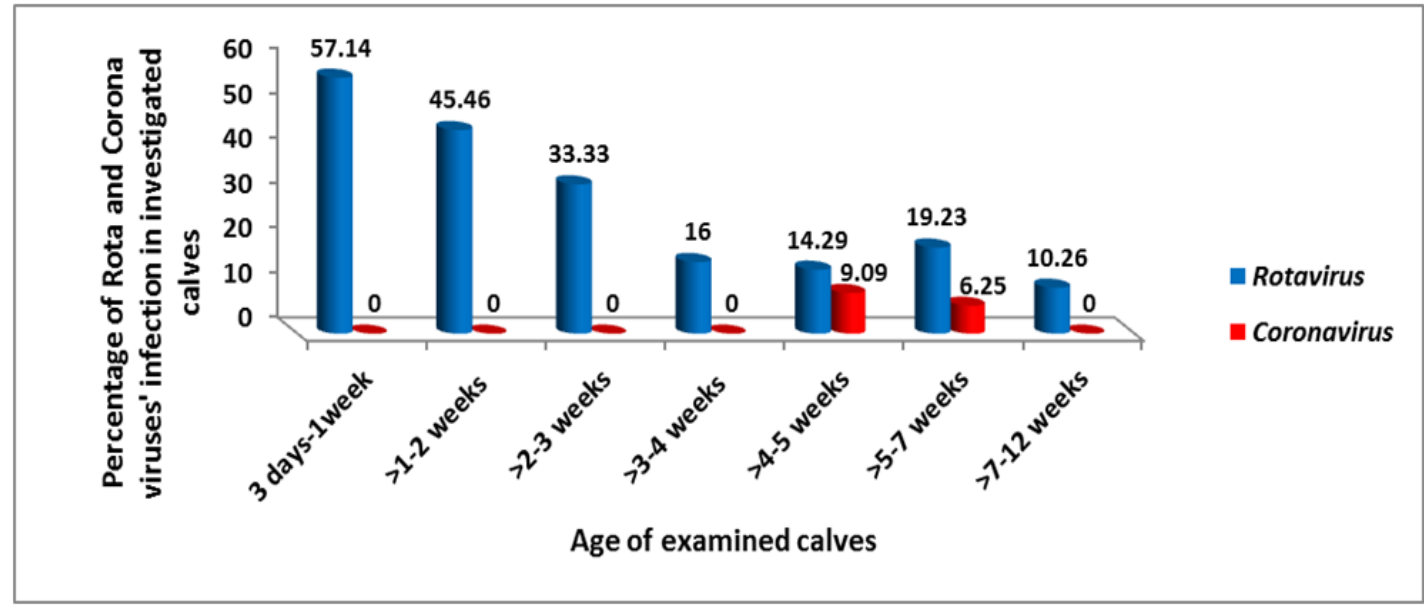

Figure 6: Age susceptibility to Rota and Corona viruses' infection in investigated calves.

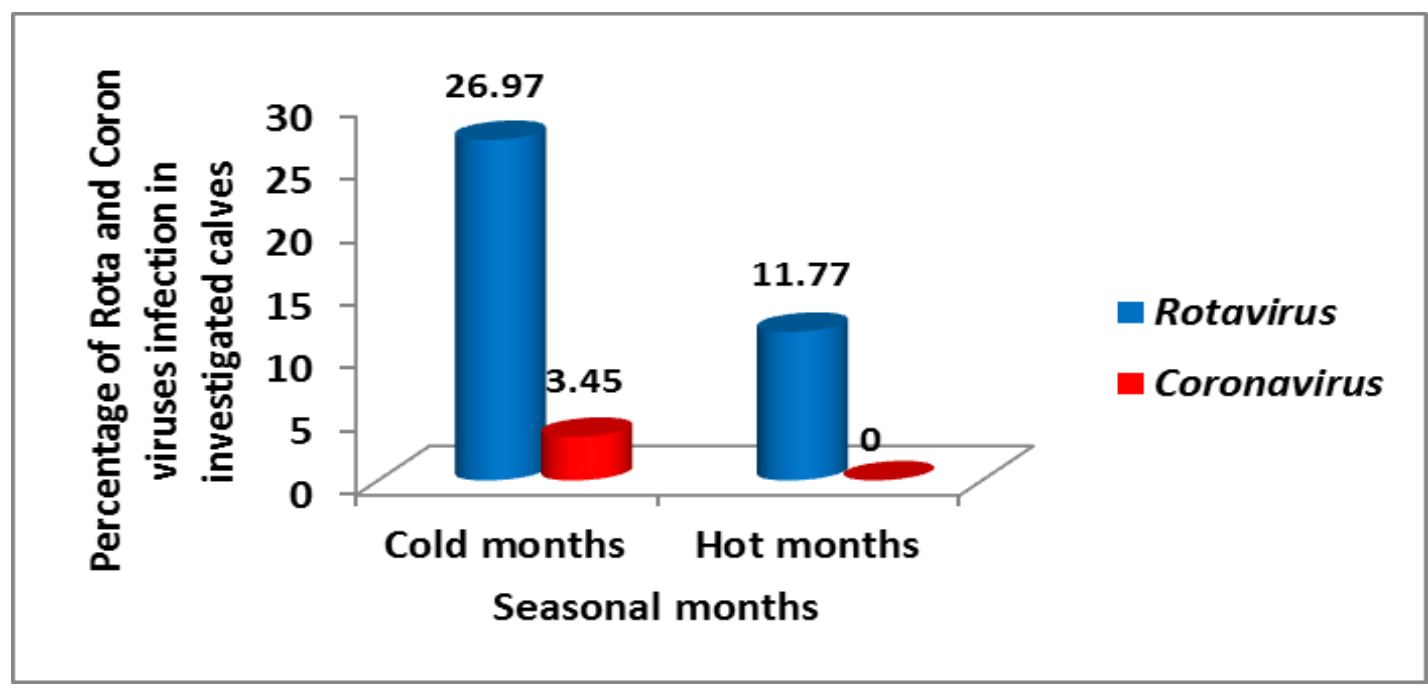

Figure 7: Detection of Rota and Corona viruses' infection in examined calves according to seasonal variation. 


\section{DISCUSSION}

Neonatal calf diarrhea is multifactorial syndrome, resulting from an interaction between calf, managemental, environmental, and nutritional in association with infectious agents. The later plays an outstanding role in calf diarrhea particularly when the hygienic measures are sublevel or bad. Viral pathogens particularly Rotavirus and Coronavirus are the most implicated pathogen of calf diarrhea (Ammar et al., 2014 and Mohammed et al., 2017). From clinical point of view, the current work revealed that Rotavirus infection was serologically and/or molecularly detected in 30 cases of examined neonatal calves $(n=140)$ with characteristic clinical features of enteritis with variable degree of diarrhea, mostly yellowish mucoid discharge with or without flakes of clotted blood, followed by dehydration and ended by lateral recumbence with signs of comatose. Some calves had straining with or without arched back. The systemic reactions were varied from case to another. Similar findings were previously observed (Dash et al., 2012 and Ammar et al., 2014). Histopathlogically, Rotavirus invades stunts and exfoliates enterocytes' villi of small intestine inducing disorder in the intestinal mucosal barriers in association with spectacular reduction in absorption capacity and in secretion of the digestive enzymes resulting profuse viscous fluid containing undigested and unabsorbed nutrients in intestinal lumen. Subsequently weakness, dehydration and thereafter acidosis due to remarkable physiological alterations and electrolytes imbalances are established (Brown et al., 2007). Bovine Coronaviruses infect calves allover the world and are pneumotropic viruses in association with their pathological role in alimentary tract (Maclachlan and Dubovi, 2011). Moreover, Brown et al. (2007) added that $\mathrm{BCoV}$ produces villus atrophy by causing lysis or exfoliation of surface of mature enterocytes and causes microscopic and macroscopic alterations in colonic epithelium of infected calves. These may interpret the voluminous mucoid and slimy, green to light-brown in color of fecal discharge in association with signs of respiratory embarrassments, in form of nasal discharge, cough and signs of dyspnea, of calves infected by Coronavirus infection. Similar clinical findings and conclusions were previously reported (Zachary and McGavin, 2013).

Serodiagnosis of Rotavirus infection in fecal samples of examined calves depending on LAT. The present study revealed that $21.43 \%$ of fecal samples were positive and this result was higher than results obtained by Radhy (2015) and Dulgheroff et al. (2016). On contrary, highest rate of Rotavirus infection in enteric calves were offered by Faheem (1999); Singh and Jhala (2011) and Izzo et al. (2012). In regarding to Coronavirus infection, an antigen detecting ELISA technique was used for serological detection of Coronavirus infection in fecal samples of examined calves. The present study revealed that 2 $(2.13 \%)$ of 94 cases were serologically positive. Similar results were reported by Safavi et al. (2012) and Bok et al. (2015). The obtained result was lower than that reported by Izzo et al. (2012) but the current result was higher than that reported by Yavru et al. (2016).Such variations in rate of infection of Rota and Corona viruses' infection in enteric calves may be attributes to geographical differences, difference in timing of samples collection, hygienic measures and environmental conditions.

Currently, fifty fecal samples of examined calves were molecularly tested by RT-PCR for detection of Rotavirus infection and revealed $8 \%$ of tested samples were positive. Comparatively, LAT and RTPCR, The 50 fecal samples were examined by both techniques. Ten samples (20\%) were positive by LAT while 4 only ( $8 \%$ ) samples were positive by RT-PCR. Similar conclusions were reported by Kumar et al. (2011). The lower prevalence of RT-PCR than LAT in present work may ascribed to three plausible reasons; a) non-specific inhibition of PCR reaction by the components of fecal samples, b) mismatches in primer binding sites or c) the sequence variation in Rotavirus genome due to segmented of RNA genome, Rotavirus is continuously changing and leading to emergence of new genotypes (Gouvea et al., 1990 and Kumar et al., 2011).

Concerning Coronavirus infection, 50 fecal samples were examined by using RT-PCR for detection of Coronavirus infection in calves and found that $2(4 \%)$ of 50 samples were positive. The current results indicated that both serological (ELISA) and molecular (RT-PCR) were efficient and sensitive \{RT-PCR was $4 \%(2 / 50)$ - ELISA was $4 \%(2 / 50)\}$. Similar results were reported by Hansa et al. (2012) who reported that all ELISA tested fecal samples were found positive by RT-PCR.

From the epidemiological point of view, the present study indicated that percent of Rotavirus infection of examined calves was $21.43 \%$ in Assiut Governorate. Lower prevalence in Assiut was reported by Abd ElRahim (1997) and Abou El-Ella et al. (2013) and higher prevalence was also reported by Faheem (1999) in Assiut Governorate. On the same manner, the rate of Coronavirus infection in the current work was $2.13 \%$ ( 2 of 94) of investigated neonatal calves in Assiut Governorate. This result was lower than that obtained by Abd El-Rahim (1997); Faheem (1999) and Abou El-Ella et al. (2013). Such diversities may attributed to differences in duration of samples collection, variation in samples size, farms management, hygienic status, environmental condition, using different techniques in diagnosis and difference in qualities and quantities of colostrum received by examined calves in the first few hours 
after calving (Abd El-Rahim, 1997; Faheem, 1999 and Ammar et al., 2014). The occurrence and distribution of Rotavirus in enteric and clinically healthy calves have been studied by (Safavi et al., 2012). In the current study, the rate of Rotavirus infection of enteric and clinically healthy calves was $23.33 \%(28 / 120)$ and $10 \%(2 / 20)$, respectively. The obtained result indicated that Rotavirus infection was higher in enteric than clinically healthy calves. This may be attributed to Rotavirus destroys enterocytes of small intestine resulting in diarrhea which is accompanied by a profuse fecal shedding of virus. The rate of Coronavirus infection of examined enteric calves was $2.20 \%$ (2/91) and no rate of infection with clinically healthy calves. This may be attributed to Coronavirus destroys enterocytes of small and large intestines resulting in diarrhea, which is accompanied by a profuse fecal shedding of virus. Regarding to locality in the present study, there was no significant difference in percent of Rota and Corona viruses' infection in examined calves of Veterinary Teaching Hospital and farms of Assiut Governorate. This may be attributed to these calves were found under same geographical, seasonal condition, method of animals husbandry, hygienic measures, managemental system and the same animals breed.

Statistical analysis of the obtained results indicated that the rate of infection with Rotavirus was decreased by increasing the age of examined calves and peak of infection was at 3 days-1week old. Singh and Jhala (2011) and Ammar et al. (2014) studied rate of Rotavirus infection in calves at different ages and their results concluded that rate of infection was highest during the first 2 week and thereafter declining by increasing the age of calves. This may be due to immune system of neonatal calves is not fully mature to handle Rotavirus pathogen (Ammar et al., 2014). Moreover, the susceptibility of calves to Rotavirus decreases with age probably due to loss of receptors on enterocytes (Udaykar et al., 2013). Lactase enzyme present in the brush border of intestinal epithelial cells that may be act as a receptor and un-coating enzyme for Rotavirus, level of lactase is highest in early life and decreases as age of calf increases so rate of infection with Rotavirus was decreased by increasing age of examined calves (McNulty, 1978). Coronavirus infection was observed among enteric calves of $>4-5$ weeks old by $9.09 \%(1 / 11)$ and $>5-7$ weeks old by $6.25 \%$ (1/16) of investigated calves. Similar results was reported by Davoudi et al. (2014) who indicated that highest prevalence rate of Coronavirus infection was seen at 2-6 weeks and least during the first week and 6-8 weeks of age. This may due to decrease of colostral antibodies present in first weeks of age (Stipp et al., 2009). In current study, absence of Coronavirus in age of 3 days- 4 weeks may be due to presence of colostral antibodies and strong local immunity in intestinal lumen that protect newly born calves against viral infection (Mayameei et al., 2010). The absence of Coronavirus in age of $>7-12$ weeks may be attributed to activation of local host immunity so increase natural resist to viral infection (Mayameei et al., 2010).

In referring to the effect of sex on distribution of infection, the analytic results indicated that there was no significant difference in rate of Rota and Corona viruses' infection between male and female calves. The same result was recorded by Radhy (2015) and Yavru et al. (2016). This may be due to the anatomical, functional and hormonal similarities of body systems of male and female calves in early ages that lead to non-particular resistance against Rota and Corona viruses' infection but degree of contamination with virus, dose of virus, exposing to stress factors, all effect on infection rate and severity in both sex of calves in same or different periodic age (Yavru et al., 2016).

In the present work, there was no significant difference in percentage of Rota and Corona viruses' infection between Native, Friesian ad Holstein breeds. Similarly, Faheem (1999) revealed that no significant difference in prevalence of Rota and Corona viruses' infection between different breeds of calves. Concerning species susceptibility, the obtained results revealed that Rotavirus infection was diagnosed in both cattle and buffalo calves' fecal samples with no significant difference, although the higher percent of Rotavirus infection in cattle's calves than buffalo calves mathematically. These findings were previously reported by El-Bagoury et al. (2014). In the present study, Coronavirus infection was diagnosed among cattle calves $(2.25 \%)$ and no infection among buffalo calves was reported. Abou El-Ella et al. (2013) found that $\mathrm{BCoV}$ was diagnosed in $8.45 \%$ of cattle calves and $5.13 \%$ in buffalo calves. This may attributed to lower susceptibility of buffalo calves than cattle calves and difference in immune status of calves.

Relationship between seasonal variations and rate of infection with Rota and Corona viruses was studied during the period of investigation and found that percent of Rotavirus infection in examined calves was high (26.97\%) in cold months of Assiut Governorate and was low $(11.77 \%)$ in hot months. Percent of Coronavirus infection was detected in cold months only by $3.45 \%$. Similar results were reported by Mushtaq et al. (2013); Mayee and Alrodhan (2014) and Asadi et al. (2015). In Egypt, most calving occur at the end of autumn and beginning of winter in which these neonatal calves are more susceptible to Rota and Corona viruses' infections. Additionally, the intestinal and serum immunoglobulin's level were decreased in autumn, winter and increased during spring, summer (Mushtaq et al., 2013 and Asadi et al., 2015). Mayee and Alrodhan (2014) indicated that 
$\mathrm{BCoV}$ was stable during cold months due to it's envelop nature, which was moderately sensitive to heat and Coronavirus was readily disseminated in winter months.

\section{CONCLUSION}

According to the results of this study and our field observation; Rota and Corona viruses play an outstanding role in causing enteritis in neonatal calves in different localities of Assiut governorate. Our attention should be directed toward these viruses in any control programs put to overcome enteritis in neonatal calves in Assiut.

\section{REFERENCES}

Abd EL-Rahim, I.H.A. (1997): Rota and/or coronavirus infections in newborn buffalo calves in Upper Egypt. $4^{\text {th }}$ Scientific Congress, Egyptian Society for cattle diseases. 7-9 December, Assiut, Egypt. 210-220.

Abou EL-Ella, G.; Mohamed, A.M. and Amer, A.A. (2013): Prevalence of enteropathogens associated with neonatal calf scour in cattle and buffalo calves using (FASTEST® Strips) rapid field test. Assiut Veterinary Medicine 59(138): 19-26.

Ammar, S.S.M.; Mokhtaria, K.; Tahar, B.B.; Aamar, A.A.; Redha, B.A.; Yuva, B.; Mohamed, H.S.; Abdellatif, N. and Laid, B. (2014): Prevalence of Rotavirus (GARV) and Coronavirus (BCoV) associated with neonatal diarrhea in calves in western Algeria. Asian Pacific Journal of Tropical Biomedicine 4(1): 318322.

Andrews, A.H.; Blowey, R.W.; Boyd, H. and Eddy, R.G. (2004): Bovine Medicine, Diseases and Husbandry of Cattle. $2^{\text {nd }}$ Edition. Oxford; Wiley-Blackwell, United Kingdom. 1.

Asadi, A.H.; Baghinezhad, M. and Asadi, H. (2015): Neonatal calf diarrhea induced by Rotavirus and Coronavirus: a review. International Journal of Biosciences 6(2): 230-236.

Bok, M.; Miño, S.; Rodriguez, D.; Badaracco, A.; Nuñes, I.; Souza, S.P.; Bilbao, G.; Louge, U. E.; Galarza, R.; Vega, C.; Odeon, A.; Saif, L.J. and Parreño, V. (2015): Molecular and antigenic characterization of bovine Coronavirus circulating in Argentinean cattle during 1994-2010. Veterinary Microbiology 181(3-4): 221-9

Brown, C.C.; Baker, D.C. and Barker, L.K. (2007): The Alimentary tract. In Jubb, Kennedy and Palmer's of Domestic Animals, Edited by Grant Maxie. $5^{\text {th }}$ Edition. Vol. II, chapter 1. Sunders LTD. 69-130.

Cho, K.O.M.; Hasuksuz, M.; Nelsen, P.R.; Chang, K.O.; Lathrof, S. and Saif, L.J. (2001): Cross protection studies between respiratory and calf diarrhea and winter dysentery Coronavirus strains in calves and RT-PCR and nested PCR for their detection. Archive Virology 146: 2401-2419.

Cockcroft, P. (2015): Bovine Medicine. $1^{\text {st }}$ Edition. India. 581.

Dash, S.K.; Kumar, K.; Goel, A. and Bhatia, A.K. (2012): Detection of Coronavirus antigen by ELISA from diarrheic cow calves in Mathura, India. Veterinary World 5(3): 166-168.

Davoudi, Y.; $\quad$ Nourmohammadzadeh, $\quad$ F.; Abdollahpour, G.; Nouri, A. and Nowrouzian, I. (2014): The prevalence of Coronavirus in fecal samples of neonatal calf diarrhea using electron microscopic examination. Iranian Journal of Veterinary Medicine 8(2):85-89.

Dulgheroff, A.C.B.; Pereira, W.A.B.; Sarmento, R.R.; Silva, G.A.V.; Naveca, F.G. and Domingues, A.L.S. (2016): Analysis of bovine Rotavirus strains circulating in diarrheic dairy calves in Uberaba, Minas Gerais, Brazil, during 20082009. Arquivo Brasileiro de Medicina Veterináriae Zootecnia (Brazilian Journal of Veterinary and Animal Science) 68(4): 10901094.

El-Bagoury, G.F.; El-Nahas, E.M.; El-Deen, S.S.S. and Salem, S.A.H. (2014): Frequency of Rotavirus detection by a sandwich ELISA in feces of diarrheic bovine calves from Qaluobia province, Egypt. Benha Veterinary Medical Journal 27(2): 341-347.

Faheem, S.M. (1999): Clinical and laboratory studies on viral enteritis in newly born calves, M.V.Sc. Thesis, Faculty of Veterinary Medicine, Assiut University, Egypt.

Fukuda, F.M.; Nagai, M.; Takai, H.; Murakami, T.; Ozawa, T.; Tsuchiaka, S.; Okazaki, S.; Katayama, Y.; Oba, M.; Nishiura, N.; Sassa, Y.; Omatsu, T.; Furuya, T.; Koyama, S.; Shirai, J.; Tsunemitsu, H.; Fujii, Y.; Katayama, K. and Mizutani, T. (2013): Detection of Bovine Group A Rotavirus Using Rapid Antigen Detection Kits, RT-PCR and Next-Generation DNA Sequencing. Journal of Veterinary Medical Science 75(12): 1651-1655.

Gouvea, V.; Glass, R.I.; Woods, P.; Taniguchi, K.; Clark, H.F.; Forrester, B. and Fang, Z.Y. (1990): Polymerase chain reaction amplification and typing of Rotavirus nucleic acid from stool specimens. Journal of Clinical Microbiology 28: 276-82.

Hansa, A.; Rai, R.B.; Wani, M.Y. and Dhama, K. (2012): ELISA and RT-PCR Based Detection of Bovine Coronavirus in Northern India. Asian Journal of Animal and Veterinary Advances. 1-10.

Izzo, M.M.; Kirkland, P.D.; Gu, X.; Lele, Y.; Gunna, A.A. and Housea, J.K. (2012): Comparisons of three diagnostic techniques for detection of Rotavirus and Coronavirus in calf faeces in 
Australia. Australian Veterinary Journal 90(4): 122-129.

Jackson, P.G.G. and Cockcroft, P.D. (2002): Clinical examination of farm animals. $1^{\text {st }}$ Edition. United Status of America. 95-101.

Kumar, M.; Bhilegaonkar, K.N. and Agarwal, R.K. (2011): Prevalence and characterization of Rotavirus from faecal samples of children and animals. Indian Journal of Animal Sciences 81 (10): 993-999.

Maclachlan, N.J. and Dubovi, E.J. (2011): Fenner's Veterinary Virology. $4^{\text {th }}$ Edition. United Status of America. 406-408, 278-281.

Mayameei, A.; Mohammadi, G.; Yavari, S.; Afshari, E. and Omidi, A. (2010): Evaluation of relationship between Rotavirus and Coronavirus infections with calf diarrhea by capture ELISA. Comparative Clinical Pathology Journal 19: 553-557.

Mayee, K.Q. and Alrodhan, M.A.N. (2014): Some epidemiological features of $\mathrm{BCoV}$ infection in Al-Qadisiya province by using real timeqPCR technique. AL-Qadisiya Journal of Veterinary Medical Science 13(2): 14-19.

McNulty, M.S. (1978): Review Article: Rotaviruses. Journal of General Virology 40:1-18.

Mohammed, F.F.; Mansour, S.M.G.; El-Araby, I.E.; Mor, S.K. and Goyal, S.M. (2017): Molecular detection of enteric viruses from diarrheic calves in Egypt. Archives Virology 162: 129137.

Mushtaq, M.H.; Saleem, M.N.; Ayyub, R.M. and Khattak, I. (2013): Challenges due to early calf mortality in dairy industry of Pakistan and strategies for improvement. Veterinária 1(1): 13-17.

Radhy, A.M. (2015): Prevalence of Rotavirus, Escherichia coli O157:H7 and Cryptosporidium spp. in feces of buffalo in Babil governorate. AL-Qadisiya Journal of Veterinary Medical Science 14(1): 75-79.
Rocha, T.G.; Silva, F.D.F.; Gregori, F.; Alfieri, A.A.; Buzinaro, M.G. and Fagliari, J.J. (2017): Longitudinal study of bovine Rotavirus group $A$ in newborn calves from vaccinated and unvaccinated dairy herds. Tropical Animal Health and Production 49:783-790.

Safavi, A.; Mohammadi, E.A.; Rad, G.R. and Naghibi, M.A. (2012): A Case-Control Study of Association between Diarrhea in Newborn Calves and Infection with Rotavirus and Coronavirus in Some Industrial Dairy Herds of Mashhad Area, Iran in 2008. Archives of Razi Institute 67(1): 35-41.

Singh, T.C. and Jhala, M.K. (2011): Comparing Relative Sensitivity and Specificity of LA and RNA-PAGE in Detecting Bovine Rotaviruses. Buffalo Bulletin 30(1): 36-44.

Sravani, G.V.D.; Kaur, G.; Chandra, M. and Dwivedi, P.N. (2014): P and G genotyping of bovine Rotavirus and its prevalence in neonatal calves. Veterinarski Arhiv 84(5): 475-484.

Stipp, D.T.; Barry, A.F.; Alfieri, A.F.; Takiuchi, E.; Amude, A.M. and Alfieri, A.A. (2009): Frequency of $\mathrm{BCoV}$ detection by a seminested PCR assay in faeces of calves from Brazilian cattle herds. Tropical Animal Health Production 41: 1563-1567.

Udaykar, A.; Sharda, R.; Malik, Y.S.; Sharma, V. and Shrivastava, N. (2013): Occurrence of group a Rotavirus in diarrheic buffalo and cow calves, Madhya Pradesh. Indian Advances in Animal and Veterinary Sciences 1 (4S): 51 -53.

Yavru, S.; Yapici, O.; Kale, M.; Sahinduran, S.; Pehlivanoglu, F.; Albay, M.K. and Avci, O. (2016): Bovine Coronavirus (BCoV) Infection in Calves with Diarrhoea and Their Dams. Acta Scientiae Veterinariae 44: 1-7.

Zachary, J.F. and McGavin, M.D. (2013): Pathologic Basis of Veterinary Disease. $5^{\text {th }}$ Edition. China. 373.

\section{عدوى فيروسات الروتا والكورونا المعوية في العجول حديثة الولادة

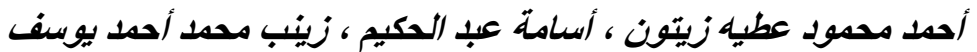

E-mail: zeinabmohammed613@yahoo.com Assiut University web-site: www.aun.edu.eg

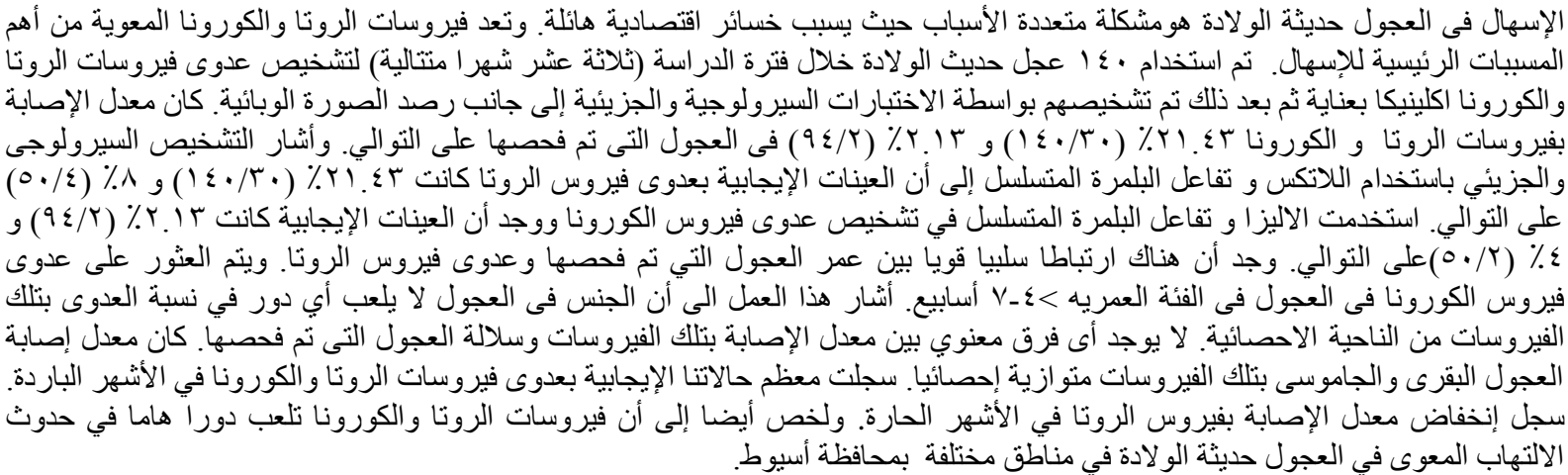

